\title{
E-Business Challenges and Directions: Important Themes from the First ICE-B Workshop
}

\author{
David Marca ${ }^{1}$, Rebecca Bulander ${ }^{2}$, Cornelia Kruslin ${ }^{3}$, \\ Boris Shishkov ${ }^{4}$, Marten van Sinderen ${ }^{5}$ \\ ${ }^{1}$ The University of Phoenix, Phoenix, U.S.A. ${ }^{2}$ Pforzheim University of Applied Science, \\ Pforzheim, Germany. ${ }^{3}$ Croatian Post and Electronic Communications Agency, Zagreb, Croatia. \\ ${ }^{4}$ The Interdisciplinary Institute for Collaboration and Research on Enterprise Systems and \\ Technology, Sophia Bulgaria. ${ }^{5}$ University of Twente, Enschede, The Netherlands.
}

\begin{abstract}
A three-day asynchronous, interactive workshop was held at ICEB'10 in Piraeus, Greece in July of 2010. This event captured conference themes for e-Business challenges and directions across four subject areas: a) e-Business applications and models, b) enterprise engineering, c) mobility, d) business collaboration and e-Services, and e) technology platforms. Quality Function Deployment (QFD) methods were used to gather, organize and evaluate themes and their ratings. This paper summarizes the most important themes rated by participants: a) Since technology is becoming more economic and social in nature, more agile and context-based application develop methods are needed. b) Enterprise engineering approaches are needed to support the design of systems that can evolve with changing stakeholder needs. c) The digital native groundswell requires changes to business models, operations, and systems to support Prosumers. d) Intelligence and interoperability are needed to address Prosumer activity and their highly customized product purchases. e) Technology platforms must rapidly and correctly adapt, provide widespread offerings and scale appropriately, in the context of changing situational contexts.
\end{abstract}

Keywords. Adaptability, agile methods, autonomic computing, business value, business-IT alignment, change management, cloud computing, collaboration, composability, context-aware computing, CRM, customer relationship management, digital native, e-Business, applications, models, enterprise ontology, enterprise engineering, e-Services, integration, intelligent user interfaces, interoperability, interoperability, mobility, physical organization, platforms, product customization, prosumer, SDLC, semantic Web, service orientation, service scalability, social CRM, social networks, societal IT, system development life cycle, ubiquity, virtual organization, virtual worlds.

\section{Workshop Overview and Important Challenges}

\subsection{Workshop Objectives and Methodology}

The International e-Business Conference (ICE-B) is one track within the International Joint Conference on e-Business and Telecommunications (ICETE). In 2010, a unique three-day interactive workshop was held for ICE-B'10. The workshop was conducted 
as an asynchronous collaborative consortium. The goal was to create a jointly authored paper on e-Business challenges and directions in the following subject areas: a) e-Business applications and models, b) enterprise engineering, c) mobility, d) business collaboration and e-Services, and e) technology platforms. The workshop had two venues: a) a traditional position paper presentation session, and b) an interactive forum which lasted all three days of ICE-B'10. Regarding the former, position paper authors became subject area leads for the joint paper. Regarding the latter, a very large physical display was maintained for recording: a) all themes generated by ICE-B'10 papers and presentation sessions, b) participants' research, and c) importance ratings. The method for information posting, organization and rating was directly from Quality Function Deployment [158]. On the last day of the workshop, ICETE'10 participants voted on the relative importance of posted themes. This paper reports on the most important themes, tying them back to ICE-B'10 conference papers and posters.

\section{2 e-Business Applications Challenges}

Economic, Technological, Societal, IT. Changes in business are usually related to the way that it must adapt to the Five Forces [131]. Nowadays, business is increasingly moving towards e-Business to stay competitive, but introducing new applications into a business may lead to a variety of problems, especially if that business is not accustomed to being supported by that technology [145]. This is particularly pronounced when a business moves from a static Web presence (i.e. a Web site or a transaction portal [30] to a dynamic Web presence (i.e. social network blog, online customer chat forum, "try before you buy" virtual experience [35] Many businesses now struggle to make Web 2.0 profitable [83].

New Technology Creates Strategic Challenges. Web 2.0 has opened up businesses to customers [66]. As a result, laggard firms are struggling to decide: how much operational transparency to provide users during an end-to-end transaction, how much investment is need to comply with new standards, how to formulate a business case that all customers can understand, and how much operation control to give up. Coupled with these decisions are dilemmas such as how much information to share, getting off the proprietary network legacy, breaking or keeping the mindset/trade-off of value versus cost, and how much product ownership to give away. In addition, traditional challenges (i.e. suppliers, new entrants, demand, etc) still exist [14].

More Agile e-Business is Needed. Application development practices from the mid1950 s to the mid-1980s concentrated on the computer. Human resistance to these applications is primarily due to bad design [21]. The practices of the mid-1980s to the mid-2000s concentrated on users, but often limited themselves to a fixed set of contexts. Resistance to using this software was due primarily to computer illiteracy or usability errors. Since the mid-2000s, user contexts are noted for being dynamic, complex, and possibly unpredictable [94]. So, e-Business applications need to have more than just interfaces and workflows that match pre-defined usage contexts [71]. Users must have the ability to design e-Business applications as they are being used. 


\subsection{Enterprise Engineering Challenges}

Understanding and Managing the Enterprise. Enterprise engineering focuses on the technology aspects of the design, analysis, implementation and operation of all elements associated with an enterprise. Such technology aspects are closely related to the analysis and design phases of the software development process [63]. During these phases, designers aim at establishing an explicit representation of the organizational and technical system processes and infrastructures in order to increase their understanding of the enterprise and make development of automated support possible. Important notions here are Enterprise Architecture (EA) and enterprise ontology. EA is a description of the information, behavior and structure aspects of an enterprise at a business, application and infrastructure level [97]. There is no common agreement on the precise model and languages to be used for accomplishing this coverage, but the importance of EA for strategic decisions across individual projects is widely recognized. A major challenge is to maintain the integrity of EA and its consistency with the continuously changing organization [63]. More formal and prescriptive approaches may be necessary to address this challenge [76]. Also new aspects may need to be considered, such as value [60] and culture [105] in order to make EA more effective for business innovation.

Enterprise ontology is a description of the concepts and relationships that can exist for a community of people of an enterprise [44]. The description is a conceptualization of knowledge in an enterprise domain, such that knowledge can be shared among stakeholders, and, using a formal knowledge representation, automated reasoning by software agents and interoperability in distributed software applications can be supported [62]. A recognized problem in this field is the agreement of a single or intermediate ontology in B2B collaboration and the alignment of top-down and bottom-up derived ontologies [67]. Also, there is a lack of frameworks to compare the strengths and weaknesses of candidate ontologies [60].

Integration and Interoperability. A related view on enterprise engineering is the modeling and integration of various organizational and technical parts of business processes [171]. The integration problem applied to the collaboration or network aspect of enterprises leads to the identification of interoperability issues. Enterprise interoperability is necessary to achieve seamless collaboration between enterprises, and to allow new business models characterized by flexible partnerships [147]. Enterprises in several domains move from highly data-driven to more cooperative information-driven, knowledge-driven environments [122] based on standards [13].

Despite the strategic importance of interoperability, and the availability of standards and architectures, several technical, semantic and organizational issues still exist [30], [171]. Ontology-based and service-oriented approaches have been proposed here as possible solution directions [66]. Business-IT alignment contributes to the effectiveness of integrated solutions, and concerns itself with how IT can help achieve business objectives and improve business performance. Alignment implies that IT and business functions should adapt their strategies together, which is a dynamic and evolutionary endeavor [107]. 


\subsection{Mobility Challenges}

Coping With Digital Natives. e-Business needs to cope with the behavior and requirements of "digital natives." The generation of the digital natives grew up with the Internet and has a great degree of competence concerning the usage of Internet services. Digital natives are well informed and assertive regarding products they want to buy [121]. They are continuously in contact with their community in social networks, where they express their positive as well as negative experiences with products, services and companies. These statements have a fundamental meaning for the purchase decision of the other members of the social network community. Bloggers write about the product or company in their blogs, videos are published via YouTube or similar sites, and the product is the subject of online discussions. Because of the wide-spread use of Smart phones, the digital natives are "always on". This means that a bad experience of one customer can develop a huge impact on a company's reputation in a larger community. This phenomenon is similar to a chain reaction. Charlene $\mathrm{Li}$ and Josh Bernoff coined the term "groundswell" for this phenomenon [101]. This means companies have to: a) place their products in social networks additionally to their regular marketing activities, b) promptly respond to negative feedback, and c) create a marketing strategy that uses mobile ads to influence digital natives in a positive way.

Totally Personalized Products. According to [133], a key factor of sustainable competitive advantage for businesses in the future is the ability to focus on the importance of individual customer experiences and tailor products accordingly to his or her individual needs. So, the customers are able to co-create the products they want to buy. This paradigm of the customer relationship where the customer feels like they are they only one, or the most important customer of a company, is called " $\mathrm{N}=1$ " [133]. To adopt this aspect to $\mathrm{m}$-Business, and to create value for the customer, $\mathrm{m}$-Services should be context aware and rapidly change to address user needs and environment [11]. One important context would be the current location of a user. To provide such context aware services the challenges are to: a) equip mobiles with several different and robust sensors to capture changing context (e.g., surrounding noise [23] and b) analyze, assemble and offer the right product to the user for the current situation).

Mass Adoption of $\mathbf{m}$-Services. Before the introduction of the iPhone, the adoption of m-Services had been modest and focused on SMS and location based services [50]. Now, there are over 42 million iPhones [98], and so its concept has been copied and AppStores (e.g., Andriod Market, Ovi Store) offer their services to the user. Today, forecasts predict the number of mobile users accessing the Internet will surpass the number of users accessing the Internet using PCs, and some also predict a significant shift from Web use to mobile application use [7]. Beside these changes, will there be barriers from the perspective of physical, cognitive, security, economic and entertainment value of m-Services for mass adoption and user acceptance? According to Ervasti and Helaakoski, the utility of m-Services has a strong impact on user attitude towards mobile services [138], and this means the added value of m-Services has yet to fully to meet user needs. Another finding is that context information for personal mServices is an important influencing factor towards user intent to buy m-Services [50]. These findings should be incorporated into the future development of m-Services. 


\subsection{Collaboration and e-Services Challenges}

Proper Inclusion of the Digital Native Population. "Digital natives” were born after 1980, after the first social digital technologies were invented. They live much of their lives online via social mediated interaction. Their notions of making friends, creating/working, experiencing music, and sharing their lives differ from those born before 1980 [121]. Sometimes called "The Net Generation," they relate to technology differently, with reflexes tuned for speed and innovation. They want freedom, choice, and customization in everything they do and buy. They enjoy conversation, not lecture, and insist on integrity underneath communications. They want to have fun at school and work, and want to learn to think for themselves. They are very willing to electronically engage, and search online about products before buying [160]. Regardless of name, this group is global in its force, scope and nature, and operates more like a population rather than a generation [121]. Thus, e-Business needs to cope with the behavior and needs of digital natives. This means managing the groundswell and the impact of the participation of this population in the context of their social network communities [133]. Specifically: a) knowledge-intensive firms must create shared interest, b) service-oriented firms must create complementary online spaces for people to discuss shared practices, and thus discover the tacit knowledge that impacts purchases, and c) honest and open dialog between customers and the sales force [93].

Offering Fully Customized Products to Consumers. Given how digital natives think, e-Business must offer totally personalized products and adjust its customer relationships in ways so customers feel like they are the only, and most important, customer [134]. The business challenge is typically called "value co-creation" [5]. Value co-creation, is an emerging innovation, marketing and business paradigm describing how customers and users are seen as active participants in the design of personalized products, services and experiences [133], [127]. Often this participation is organized via the Internet to enable the opportunity for customers to integrate their knowledge, experience and skills into existing, modified or entirely new market offerings reflecting their personal preferences, needs and contexts [142]. For example, in the case of global software development, the platforms of electronic engagement are: a) individual connection, b) electronic Community, c) resource sharing, and thus product personalization or co-production can happen via any of these forms of engagement [159]. Therefore, e-Business must have a multi-pronged approach to digital natives and customized products. In short, it must have: a) a global strategy, b) integration of product-system-business processes, c) rapid response, d) reconfigurable manufacturing systems, e) innovative products, f) products able to be highly personalized, g) data driven operations, and h) flexible strategic alliances [176].

\section{Matching Pragmatic Interoperability to Semantic Interoperability}

Interoperability at the service level is characterized by three aspects: syntactic, semantic and pragmatic [170]. Semantic Interoperability is the ability of communicating entities (not only computers) to share unambiguous meaning [130]. Syntactic Interoperability, provided by languages such as XML, involves a common data format and protocol to organize data so that: a) information can be correctly interpreted from its structure, and b) syntactic errors can be detected [8]. However, data represented using 
one syntax may not be accurately translated into a different syntax [65]. Interoperability is a multifaceted problem caused by issues such as: a) organizational incompatibilities buried deep within collaborating enterprises, b) architectural mismatches, c) defective assumptions about application behavior, and d) mismatched properties within business collaboration models. Thus, pragmatic interoperability (i.e. the implementation) is hard to match to semantic interoperability (i.e. what was intended). One approach: build taxonomies of independent aspects, each being a different view of enterprise computing. A clean separation makes easier the identification interoperability requirements [140]. Ontology can aid in the construction of this taxonomy. In general, a single ontology containing every term used in every computer application is thought to be impossible, because of the speed and dynamics of how people construct business vocabulary. However, it seems possible to define a set of very primitive terms that can then be used to create concepts for applications or ontologies [43].

\subsection{Technology Platforms Challenges}

Technology platforms play the crucial role of enabling e-business developments, by providing the possibility for flexible service invocations. Enabling the construction of flexible and loosely coupled business applications, spanning over different networked enterprises capable of interconnecting their applications and share data by combining a set of services, service-oriented technology platforms represent an essential foundation for e-business interactions [20]. Such kind of platforms are also expected to bridge technology and real life, with regard to how technology is incorporated by reallife systems which are human-centered, taking into account that e-Business means now much more than electronic data interchange. Three key issues in this regard are Autonomy, Adaptability, and Context Awareness:

- $\quad$ Autonomy: how modules can maintain, in some cases, their own autonomic functioning, "deciding” on their own what to do next.

- Adaptability: how automated systems can adapt to a changing environment.

- $\quad$ Context-Awareness: how systems can deliver services in line with the user's situational context, plus the concerns of mobility, security, and collaboration.

One consideration of technology platforms relates to two desired features essentially important: service orientation and service scalability.

Service Orientation. Service orientation is required for achieving a wide spread of offered technical IT facilitations through advanced ICT platforms, unrestricted by the way the service delivering components are implemented and also by other low-level issues. Service-oriented platforms should hence allow for an easy way of pushing forward business goals through formulated requests at high level, abstracting from the underlying technical details. This can only be accomplished through "wrapping” technology and accessing it through standardized interfaces through which a platform utilizes service invocations. Although this has already been well-established as a research vision [3] it is still missing a wide practical accomplishment.

Service Scalability. Scalability is significant because of the open nature of most technology platforms [177], which appear as facilities often supporting interactions and/or 
collaboration. This means that scaling up to hundreds or thousands of users and involved organizations may be needed. In supply-chain, for instance, which much relies on e-Business facilitation [154] is often necessary to serve hundreds of suppliers and thousands of users, allowing them to adequately profile their requests as well as to establish and maintain dynamic collaborations, relying on diverse services provided by different service-providers. To solve this, platforms are often "tempted" to enforce standards, which makes their support of limited use to many customers or they allow for dynamic, autonomic support which nevertheless handles a limited number of "scenarios." We hence need a wider degree of customization through which users would be left to shape the platform support according to their preferences, while being flexibly led in establishing this, for guaranteeing that they would only go for requests that are adequate with regard to what the platform is providing.

\section{2 e-Business Applications Directions}

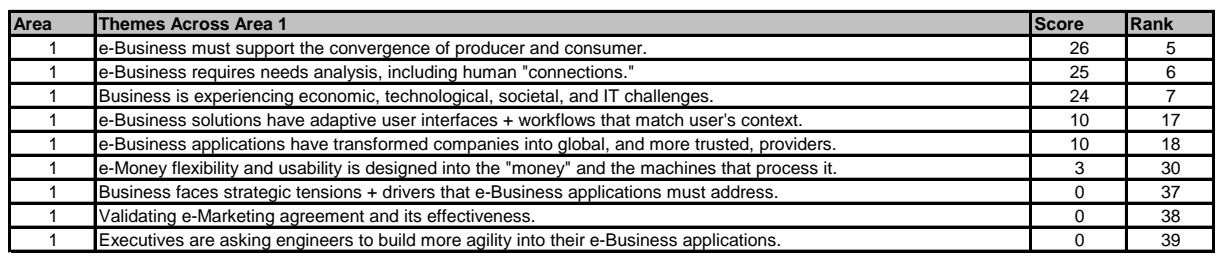

Table 1. Conference Themes and Relative Importance for e-Business Applications

(Scores are relative importance ratings. The ranking was done across all subject areas.)

\subsection{Eliciting Context-Based Usage and Operational Requirements}

Business applications are becoming easier to use, and are now being used by consumers with different technical knowledge and skills [50]. Part of this trend is due to application developers, who are improving their abilities to: a) understand how to help consumers carry out their everyday work, and b) serve the business and operational needs of producers [145].

Consumers are more and more often actively involved in the product design and development process in order to get the application that will cover all or most of their business or working needs and will be usable and understandable to them [143]. Producers as well need consumers to contextually specify the exact situations in which they will use the application, and to specify those requirements in non-technical language [71] including operational constraints. Since consumers with less technical experience usually describe their needs by giving concrete examples, involving them can provide producers with more concrete and straightforward information about the expected product [185]. The framework and the goals of existing and future application usage can be better determined if explained with concrete examples using simple language [11]. Application designers will then be able to transform those requirements into technical language, and thus implement e-Business applications with fewer errors.

The current direction of merging the producer and consumer into the so-called "prosumer" [164] brings new value to application development, especially to require- 
ments elicitation [23]. In the end, consumers will be more satisfied with the result, such as the utility of the product or service [186] and simpler and more rational procedures for installation and use [2]. Having the prosumer actively involved in the process of e-Business development is a direction which can improve the quality of life of life for the consumer [58] and give friendlier face to the provider [84].

\subsection{Positive Changes to the System Development Life Cycle (SDLC)}

Improved requirements elicitation is part of a larger trend of improved practices throughout the System Development Life Cycle (SDLC) [169]. These practices start when the need for a system is recognized [105] and carry through to actual delivery and deployment of the system [186]. Here are the improved practices discussed during paper presentations at the conference:

- $\quad$ Project Scope and Planning: a) ontology for consistent understanding of the problem [67], b) buy versus build decisions that best meet business needs [1].

- $\quad$ Requirements Elicitation: a) in-depth understanding of the user's context [105] and [180] b) accurate transactional requirements [116] and [26].

- Solution Design: a) designing flexible business processes into applications [166] b) software versions of rules and standards from business models [13].

- $\quad$ Solution Implementation: a) implementation for interoperability [123] and [52] b) thorough and dependable testing [55] and [76].

Together, these practices address some key decision-making that occurs during the SDLC, and provide a three-way benefit to project stakeholders. First, executives are more assured that the way they designed the business and intend it to operate will actually be realized in the e-Business [14]. Second, the users will experience technology that has a higher likelihood of matching: a) the different work/leisure contexts in which they find themselves [180] b) their changing mental perspectives as their context changes [72] and c) specifics of their activities in any given work/leisure context [129]. Third, system developers spend less time in each SDLC phase on standards, rules, and agreements already decided upon by both the business and the users [59]. This win-win-win situation is the direct result of the business making an investment in better practices and tools [126] and the willingness of developers and users to collaborate during application development [145].

\subsection{Widening Scope of e-Business Applications}

Business Scope. While some markets continue to grow, business is attempting to resolve the sometimes conflicting requirements and constraints of the economic, technological, societal and IT perspectives [126]. In response, business models are being developed to address customer needs while also addressing industry and government standards and regulations [145]. In addition, the Internet has become part of everyday life, and in the case of "digital natives," life is lived on technology [121] The outcome of a whole population geared to electronic (versus brick and mortar) commerce means the scope of its applications must move beyond ground stores and supply chains and to the Internet. In other words, nowadays a business without an Internet presence is 
risking market penetration in significant ways [162]. For future success e-Business applications must be facile in social networks and with multimedia [74].

Consumer Scope. Business scope and consumer scope are intertwined. From the consumer perspective, digital natives expect anything-anywhere-anytime [118]. So, eBusiness is trying to spread into every corner of the Internet, such as: blogs, wikis, portals, and social networks - in other words, e-Business must now be managed, or business will find the well-known phenomenon of "scope creep" to severely impact profitability [135]. If managed properly, consumers stand to gain many benefits; for example: a) personalized products [15], [181], b) better and simpler services [11], c) more intuitive and natural user interfaces [16], d) novel ways to transact [116] and e) application behavior sensitive to the user's current context [104].

Functional Scope. Some e-Business applications are attempting to tackle business strategy in an attempt to satisfy widening business and user scopes [53] (e.g. e-Voting, e-Health, e-Delivery, e-Careers, e-Procurement, e-Complaints, e-Banking, and eBilling. Managing the functional scope of such applications can partially be addressed via standard: a) Web services that communicate with consumers through a generic Web-based interface using standardized information [61], b) business models [52], c) business ontology [67], and d) interoperability [123]. Clearly, growth and maturity of all these standards are a major e-Business direction.

\section{4 “How Much Technology" is a User Decision}

Ultimately, the main purpose of any e-Business application is to help consumers carry out their desired activities as simply, quickly and reliably as possible [173]. As eBusiness applications become more functionally rich, more adaptable, and more interactive, the user needs be put in control of just how much technology should be used in any given life context [156]. This choice is not just a simple matter of better speed, easier use, simpler process, or any other similar benefit of current e-Business applications [161]. Instead, it is a matter of user comfort with the decision-making process in whatever life context they are now experiencing [87].

While these ideas are not new, we see the next immediate generation of e-Business applications being on the tipping point of providing functions and information in ways that allows users to selectively choose, or ignore entirely, assistance and/or data at any given moment in time to at any breadth or depth. Both research and literature are not mature in this area, and we see much growth in this direction. This direction must answer the question "How much technology is really needed to make an optimal decision?" [109] A related question might be "Should e-Business applications have embedded AI technology so that they learn over time and then infer [54] to not offer assistance and/or information [49] when the user has re-entered a known life context and has previously chosen to ignore similar assistance and/or data?

We acknowledge the research and hard work of the many hundreds of scholars in the areas of participatory design [48] user-centered design [120] collaborative design [164] and many similar concepts, methods and techniques for allowing users to participate in the design of computer artifacts. Up to now, user participation has been li- 
mited to the development stage of a technology. But, with the advent of cloud computing [9], composable Web services [75], ontologies [60], and maturing of artificial intelligence technology [54], we see a potential for the e-Business application development path that allows users to design technology while it is being used. This is an interesting and an exciting direction, and we expect much growth in this area.

\section{Enterprise Engineering Directions}

\begin{tabular}{|c|l|c|c|}
\hline Area & Themes Across Area 2 & Score & Rank \\
\hline 2 & Design systems that can evolve with changing business needs. & 38 & 1 \\
\hline 2 & Value modeling / analysis is needed in enterprise application development. & 33 & 3 \\
\hline 2 & e-Commerce (physical to digital to virtual) is altering business economics. & 14 & 12 \\
\hline 2 & Web 2.0 is focused on entrepreneurship as part of Enterprise 2.0. & 10 & 19 \\
\hline 2 & Business transaction standards enable B2B interoperability. & 7 & 21 \\
\hline 2 & Analytical CRM: discover trends + opportunities corresponding to "digital native" reqts + the social network. & 7 & 22 \\
\hline 2 & Companies want their e-Business solutions to grow into global solutions. & 6 & 26 \\
\hline 2 & The e-Business model must address the explicit design of culture into the solution. & 4 & 27 \\
\hline 2 & e-Business solutions are becoming a heterogeneous collection of well-integrated components. & 4 & 28 \\
\hline 2 & Companies are building proprietary ontologies to describe their business + how it operates. & 0 & 40 \\
\hline 2 & Holistic business transformation framework enables physical --> digital --> virtual path. & 0 & 41 \\
\hline 2 & Adopt a meta-design paradigm to design systems that can evolve. & 0 & 42 \\
\hline
\end{tabular}

Table 2. Conference Themes and Relative Importance for Enterprise Engineering (Scores are relative importance ratings. The ranking was done across all subject areas.)

\subsection{Coping with Societal, Business and Technology Change}

A major theme in enterprise engineering is dealing with change: business environments are continuously changing, due market or technology developments. If business organizations and their supporting IT systems do not evolve in sync, businesses would experience increasingly less effective systems. Therefore, the ability to adapt while keeping alignment between business and IT has emerged as an important factor for successful business operation. Initially, research focused on frameworks that help to understand, analyze and construct business-IT alignment. With proper alignment, the potential of IT systems is fully exploited to achieve business goals and objectives. Such frameworks have been discussed by [183], [107], Enterprise Architecture (EA) subsequently emerged as an important discipline to deal with alignment issues, next to issues of integration and complexity [188], [189].

The evolution of the Internet towards a business enabler [190] has important implications for business organizations: not only will advance IT, reduce costs, and increase productivity, it will also enable novel business models with corresponding organizational transformations. In other words, Internet developments such as electronic marketplaces, business service ecosystems and market-oriented clouds [191], [192] push business organizations to make corresponding organizational changes. These changes are not merely optional, but may be necessary to exploit these opportunities and to remain competitive or excel in their line of business.

Consequently, business-IT alignment becomes even more challenging. Organizational changes may occur more frequent, following the pace of technology development, and they will extend across organizational boundaries, due to the collaborative nature of modern ICT-based business. The role of EA remains prominent, however it is important to consider alignment as a continuous process that is addressed with an 
evolving EA [169]. The EA lifecycle consists of multiple improvement cycles, going through definition-implementation-execution-refinement phases, in which market and technology trends can be taken into account [193]. In order to ensure the integrity of EA across business, application and infrastructure levels, the application of modeldriven approaches may be useful and should be further investigated [194], [191]. Furthermore, in order to guarantee consistency with the implemented enterprise information system, architecture reconstruction approaches [195] may be applied, acknowledging that EA cannot always enforce conforming implementations but may itself be made conformant to reality by using bottom-up knowledge.

\subsection{Addressing Stakeholder Values}

Many promising IT applications and services are not commercially successful due to being too much technology-biased. In order to be successful, business aspects should be carefully considered during design and implementation, leading to a clear business plan [196] with a sound value proposition [59].

Each intended partner or stakeholder will only enter a proposed collaboration for a new business service if the benefits of participation are considered to outweigh the costs. Moreover, a participant (or participant role) can be essential for the collaboration, in the sense that without this participant (role) the service cannot be introduced or provided, e.g. because of lack of budget, expertise or infrastructure. In this setting, benefits and costs are not necessarily only or directly related to monetary aspects. For example, benefits may be the increase of recognition, friendship, publicity, knowledge or ownership. Costs may be the decrease of any of these properties or assets. In any case, benefits and costs may be valued differently by different partners and stakeholders. For a business service to be successful, each participant should perceive the collaboration as being profitable, i.e. having net benefits for its particular situation and preferences. Even if a new service has clear overall benefits over an existing situation, successful introduction or operation may not occur because the distribution of benefits and costs is unbalanced: some participants benefit more than other, or some participants pay the costs while other participants enjoy the benefits. Since situations and preferences may change in time, for each individual participant, it is important to maintain value propositions in order to keep essential participants onboard.

Although this all seems obvious, in practice many technology-oriented projects still start off without considering the business case. Or, they make important design decisions without taking business aspects into account. Fortunately, the maturing of ebusiness technology also led to an increased interest in market exploitation opportunities, which in turn shifted attention to business models. Several frameworks for understanding and analyzing e-business models have been proposed [197], [198]. These are complemented with various accepted business modeling techniques, such as ResourceEvent-Agent (REA), Business Model Ontology (BMO) and e3value. The latter focuses on value models that capture the economic value exchange in a business network, and therefore best fits the concern expressed above. 
E3value has originally been proposed by [60] and since then has been extended and applied for various purposes. Since value modeling must be considered in the broader scope of enterprise engineering, value-based business-IT alignment must be addressed [199]. This puts forward issues of consistency and transformations between the value model and various other models in the context of enterprise architecture. For example, the relationship between a value model and a goal model is studied in [200] and between a value model and a process model in [201], [199]. A systematic approach for transforming a value model into a coordination process model is proposed in [202]. Also, attention has been paid to the creating value models for business collaborations [203] and adapting B2B processes in case of changing requirements [204]. Because of the increasingly important role of service-oriented architectures for enterprise systems, value-based service analysis has been considered in [205].

\subsection{Migration from Physical to Digital to Virtual}

With the development of the Internet as a unified and global infrastructure for communication and access to information, commerce entered the digital era. This era is characterized by a new form of commerce - e-commerce - empowered by the Internet and associated technologies, which complement traditional, physical commerce. Ecommerce facilitates the transaction of "old-fashioned" goods and services. However, it also allows new value-added services as well as fundamentally different products, namely digital products [176]. Currently, another development can be observed, which can be seen as a shift to the virtual. This shift, already foreseen more than a decade ago [206], will bring new ways of service interactions based on computer representations of people, products, processes and places. Examples are digital negotiation agents, e-stores, virtual processes for supply chains, and avatars [207].

The move to virtual is reinforced by the current phase of evolution that the Internet is undergoing, which will lead to what is being called the Future Internet [208]. The Future Internet embraces two important concepts: the Internet of Things (IoT) and the Internet of Services (IoS). The former is based on advances in pervasive computing and ambient intelligence, which allows embedded computation and communication capabilities in daily objects, making them identifiable, traceable and controllable from remote locations. This allows new monitoring and control applications, such as tracing and tracking, plus interaction between the physical world and the digital world [209]. It also enables new context-aware services [210]. These services adapt the interaction with their user environment dependent on the context -state or state changes in the physical world- that is inferred from data obtained from context sensors.

IoS entails the emergence of a global and dynamic services marketplace [211]. In the IoS vision, business services are dynamically created and adapted to match demand, supply and available partnerships [213]. Further, new deployment and delivery models can be used, enabling on-demand rapid provisioning of virtual machines, platforms and services with pay-per-use [213], [192]. E-commerce and virtual markets based on the Future Internet cause challenges for enterprise engineering. Current research provides directions to address these challenges, including: serious gaming [23], business transformation processes [84], [169], and business process flexibility [166]. 


\section{Mobility Directions}

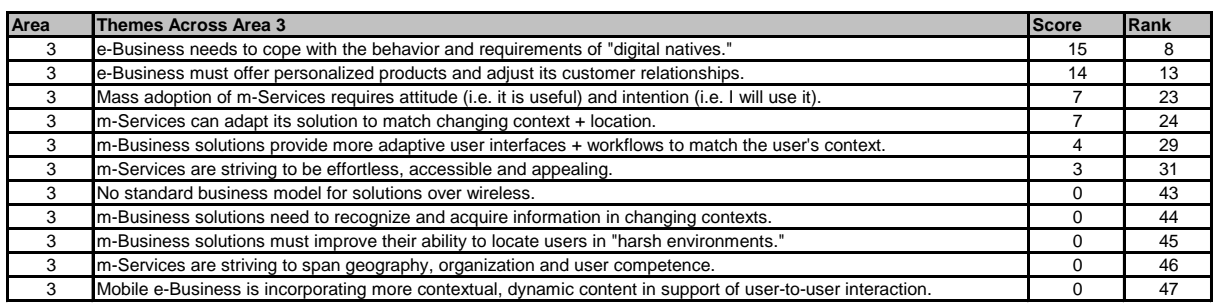

Table 3. Conference Themes and Relative Importance for Mobility

(Scores are relative importance ratings. The ranking was done across all subject areas.)

\subsection{Mobility and m-Services}

The topic "mobility" in ICE-B focused more on the side of m-Services and mobile technology than on the side of hardware or provider networks. The term "m-Services" stands for mobile services which are services where the clients are mobile terminals (MT) and at least the access network is a wireless one. Examples for MT include cellular phones, personal digital assistants or smart phones. The ubiquitous character of MT is essential: people can carry them around with themselves most of the day in turned on state. When we use the term "mobile service" we actually mean mobile and wireless data services with added value by providing additional information for a user [38]. A thematic analysis based on ICE-B 2010 papers, ICETE 2010 keynotes and some important e-business publications has been conducted. An overview of the results of this analysis for mobility is shown in Table 3.

\subsection{Context Awareness of m-Services}

The term "context," with regard to mobile applications, was introduced by [144] and is a set of information that describes the current situation of a user. A context sensitive application makes use of this information to adapt itself to the needs of the user. For mobile applications this is especially important, since the terminals have a limited interface for interaction with the user, e.g., small displays or no full keyboard. Context information can be differentiated by two distinctions [22]: 1) the privacy level (public and private) and 2) the degrees of variability (static, semi-static or dynamic). One special context is the location of a user. It would be classified as "private" and "dynamic". A service that evaluates the location of at least one mobile device during execution is called "Location Based Service" (LBS) [36]. Until 2009, LBS has been one of the most popular and used services for mobile devices [50]. Since the availability of the iPhone, which has a wide variety of application services, the socalled "apps," caused other services to become more attractive [98]. An application or service is context-aware when it adapts itself according to context information, so that it offers appropriate services corresponding to the user's situation. This aspect of context awareness is very important for the private use of application services and 
even more for business use (e.g., for mobile sales and service representatives or mobile workers). Thus, the quality of the context information plus the analytical combination to come to the right conclusion about the user's current situation can be seen as one determining factor in the adoption process of application services [11]. Summing up, one direction in mobility will be that application services are using and combining several context services so that they can exactly adapt their services to the current context and situation of a user and offer appropriate service.

\section{3 m-Services and Social Networks}

It is important to note that there have been recent and significant changes in the use of media plus the overall behavior of consumers. This is affecting m-Services and their design. In short, the mobile device is not only for direct communication, but is also for real-time feedback. According to the Interone study, digital natives are using laptops and smart phones while also watching TV, in order to search for additional information or as a feedback channel to respond to quiz games or opinion surveys [78]. For companies, this means addressing this behavior when placing information and advertisements in TV shows and when offering games or surveys. Since the great success of the iPhone and the versatile offer of applications in different application stores [98], new possibilities in many ways have arrived. Here are just a few examples:

Always On: Because of being "always on” users have more flexibility and independence in planning activities with friends [41] when shopping or enjoying entertainment. This will have an impact on business models, range of coverage and types of communication [78]. Nowadays, people have new ways to interact with their environment (e.g., respond to an advertisement when passing by a shop). Virtual services enrich the user's reality with additional information. One instance of this is a new kind of navigation enriched with additional information (e.g., a city tour on a Smartphone with historical information to important buildings and nice places to have a coffee, and another option might be to get a city tour as an audio guided tour). So, because of being "always on" there are increased opportunities for mobile learning. The offer for new applications for mobile and also social learning is growing [89]. Therefore, “apps” which use context information like the location, a camera, a microphone or a motion device can realize great potential of mobile terminals [78].

“I like it" button. Because digital natives want to be where their friends are, they primarily maintain their social contracts to friends in social networks, where they can reach them always and everywhere. In social networks they can share their preference for things with their friends or spontaneous express themselves by pressing the button "I like it". Instead of the ranking of the links the amount of clicked likes of a product now is important. Respective buying decisions these personal customer experiences are getting more and more important. Through social and mobile media the consumption of media, the communication and the shopping will come closer together [78]. This will impact product placement and advertisements. Consequently some firms already offer products in a social network. 
Increase of Online Buying. Due to the personalized "reach out” to potential customers with mobile advertisement plus the improved usability of mobile devices, ads can not only be used to inform and lead to a buying decision but also lead to an online purchase. This will be positively influenced because the potential customer has the possibility to compare prices and to confirm his decision by recommendations of his friends. This can also be named as "social mobile commerce" [45], [78].

Customer Managed Relations. Due to the versatile information in social networks plus context information such as user location, completely new interconnections are possible for optimally building relationships to potential customers. A new dimension of Customer Relationship Management (CRM) is emerging due to social network users being able to converse directly with companies regarding new products and customization possibilities. Thus, Customer Managed Relations [100] is a new trend.

Online and Offline are Merging. Applying special m-Services views of real world can be expanded with information in computer generated imagery. The physical and virtual reality is merging; this is also called "augmented reality" [103]. Gartner Research identified augmented reality as one of the top ten most disruptive new technologies from 2008 to 2012 [57]. Using such an m-Service, for example using www.wikitude.org, people can track - using their smart phones - objects at a special location, called point-of-interest, thereby enriching themselves with digital information and/or reading the digital graffiti messages of other users. Digital information can be open to all or limited to the contracts of the social network of one user.

\section{4 m-Service Security Gaps}

Mobile-Specific Security Gaps. Mobile devices are used by a majority of people as a personal assistant, and are taken everywhere. Thus, the possibility that these devices get lost or are stolen is real. This can result in unauthorized individuals gaining large amounts of confidential data (e.g. telephone numbers, addresses, or financial data) or even access to mission-critical systems if the device contains business data. In another scenario, if an unauthorized person "borrows" an unattended mobile computer, he or she may gain access to confidential systems. Additionally, wireless data communications are much more vulnerable to attacks than conventional "wired" communication, because they use "air," thus can be more easily accessed. Since the encryption of data to ensure privacy and integrity can be cracked [39], new technologies and concepts for preventing unauthorized data access and bolstering security will be necessary.

Location Privacy Gaps. Apart from the disclosure of user location by that user such as publishing a rectangle that contains the user's actual whereabouts - mobile devices must protect user's location and context information from unauthorized others. According to one study [37], many people do not want to be tracked by others without their knowing about it. Also, there are various ways to abuse user information. For example, one might be able to resolve a user's name based on just location information. To ensure the privacy of actual user locations, the development of approaches to prevent such location information misuse is an important direction. 


\section{Collaboration and e-Services Directions}

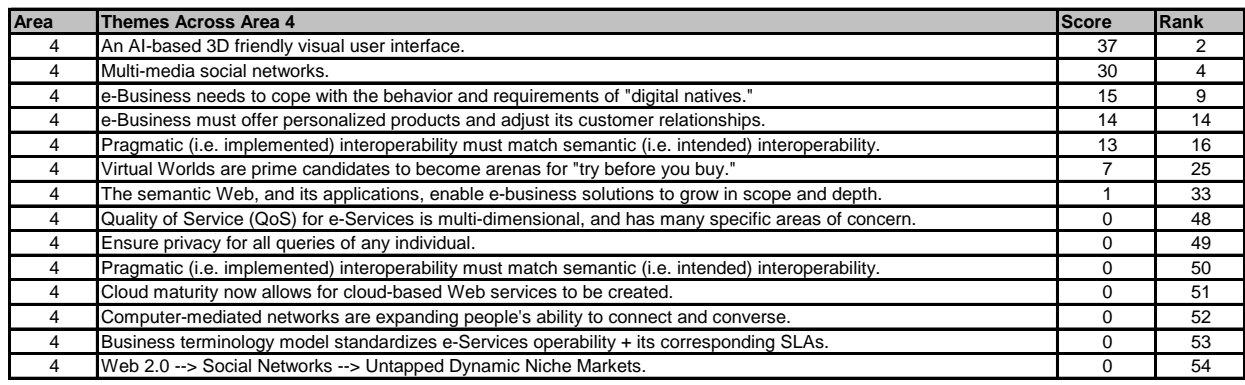

Table 4.Conference Themes and Relative Importance for Collaboration and e-Services (Scores are relative importance ratings. The ranking was done across all subject areas.)

\subsection{Evolving Ubiquity and Ability of Intelligent User Interfaces}

Intelligent user interfaces apply artificial intelligence to the problem of humanmachine interaction [46]. As user interfaces become more aware [175], they offer people more assistance with their tasks. One kind of user interface agent is called a "wizard" [10]. These agents provide task assistance by breaking the human endeavor into an often linear series of steps and presenting the steps to a person, one at a time. Another kind of user interface agent is called a "guide" [10]. Typically, guides provide assistance by monitoring a person's interaction with their immediate environment, and then presenting appropriate information, such as: highlighted important things to now consider, a set of choices, or the next best possible steps.

Over the last ten years, wizards and guides have appeared on an increasing number of diverse of computerized devices [119]: hand-held personal digital assistants, cell phones, pagers, pens, notepads, desk and wall-size computers, and also in everyday objects. The increasing connectivity of computers, started by the World Wide Web and continuing with ubiquitous computing, bolstered this proliferation. Also, recognition-based interfaces, especially speech [132], and vision systems are now becoming available to the general public, as well the need for 3D [102], customization [148] and scripting [82].

In 2010, we see the fusion of artificial intelligence, visualization, and Web 2.0 creating interfaces not thought of ten years ago: a) recommender systems based on user preferences [106] or by the history and genealogy of the user's information [81], b) high adaptability using software ontologies [16], c) personalization governed by the user's social networks [15] or by the social tagging implied by the user's searches or Web navigation [56], d) unexpected and highly useful data generated by contextaware mashups [115] and spatial hypertext [90], and e) machine learning based on the user's evolving vocabulary [79] or the user's prior personalization choices [181]. The availability and low cost cloud computing now provides storage and processing to implement far more sophisticated approaches than the ones mentioned above. 


\subsection{Multimedia Social Networks Are Better Understood and Utilized}

The growth of multimedia social networks on the Internet is revolutionizing content distribution and social interaction, and has led to a new research area, called social multimedia computing. Included in this area are: contextualized media understanding, cooperative multimedia networking, multimedia interaction dynamics, and social multi-media community analysis [162]. This research area is crucial to e-Business, because companies can be more successful if they know such things as: a) how social multimedia is used to discover relationships and connections, b) how identity can be reliably verified, and c) how to properly cascade authorization to view data [91]. eBusiness is also in a new domain of knowledge acquisition, because traditional marketing studies do not uncover key facts about customers and buying patterns. For example, knowledge discovery in blogs is different than knowledge discovery in databases or documents: clustering, decomposition and ranking are key techniques [96].

Even simple questions do not yet have good answers. For example: Why do people connect in social networks? Is it common interest? Is it friendships? Homophily (likemindedness) is not yet well understood [99]. We do know that connection patterns in multimedia social networks evolve. For example, communities grow quickly at the beginning of an episode. The resulting connection patterns often create "small worlds" which can affect consumer patterns. In addition, strong cultural influences can bias the final purchase. For example, in some countries, face-to-face dialog must take place after online dialog before a purchase is made [174]. However, we do have some important answers that can immediately impact e-Business design. For example, current methods for analyzing the behavior of users who share multimedia in peer-to-peer live-streaming social networks have shed light on human dynamics such as cheating, malicious activity, and attacking. As a result, strategies now exist to: a) stimulate user cooperation, b) achieve cheat free interaction, c) provide attack resistance, and d) help provide reliable services [106].

Technical directions are also promising. For example, new-generation smart phones enable learning, visualizing, and sharing data about peoples' daily activities. Through smart phones, users exchange multimedia data (e.g. video, audio, images), and wireless users in physical proximity can share these data via spontaneous social interactions triggered by user profile exchanges. Recent algorithms now exist to create fast and efficient connections and data transfers using a topology overlay [25]. Such multimedia file sharing has exploded in large-scale multimedia social network communities such as Napster, flickr and YouTube, and consumes $43 \%$ of the overall bandwidth, which is about three times of all WWW traffic. This consumption is driving innovation in efficient, scalable and robust data sharing strategies. For example, signal processing is being used to model, analyze and perform behavior forensics on multimedia social networks (i.e. fingerprinting use), for the purpose of designing more secure and personalized devices [186]. Other examples include: annotating images using personal and social network contexts [150] and event annotation [187].

(C)Authors. (2011). in e-Business and Telecommunications, (ed.) Filipe, J., Obaidat, M. 


\subsection{Virtual Worlds for Consumer-related Populations, Expertise and Things}

Virtual worlds have become very popular, and there is a very strong trend towards larger worlds and more user generated content, including 3D content [74]. Research has shown that "try before you buy" is part of the digital native's mentality [121], and virtual worlds already provide interactive forums where potential buyers can try products or speak with product critics or evangelists, such as in Second Life [17]. Based on these experiences, there is no reason why virtual worlds in general cannot move out the gaming arena and into the e-Business arena: the connecting, interacting, and entertaining nature of Virtual Worlds makes them prime candidates to become arenas for "try before you buy" [108]. And research, such as using P2P content delivery for making real-time, multimedia content streaming more efficient [74] continues to make virtual worlds faster, and hence more life-like, for its user populations.

From a social perspective, one can envision that, as virtual worlds become interactive forums for consumerism, there could be an explosion of virtual population births. Such populations could be comprised of digital natives who would get paid for providing product/service experience/advice. A rise of "micro-nationals" around a core idea, core belief, common work task, product use, and so, may soon occur. And such populations would be just as aligned to their commonly held agreements as they are with their current nationality [149]. Understanding user behaviors in virtual worlds is also valuable for e-Business. For example, participatory sensing - the process whereby individuals and communities use ever-more-capable mobile phones and cloud computing to collect and analyze data for use in discovery [51] - can shed light on buying intent [179]. As these micro-populations are born, they become new markets, and to exploit such markets, as mentioned earlier in this Section, e-Business activities associated with the virtual community must not merely coincide with its social interactions, but be embedded within them [12].

From a technical perspective, the door is now open for virtual worlds to unite with The Internet of Things [118]. This technology merger holds great promise for eBusiness. To explain: The concept of embedded interaction is very present in virtual worlds, even though "things" are not physical. No reason why virtual worlds cannot connect into the real world. Then, the current issues surrounding the Internet of Things apply [92]. And the virtual (as opposed to real) nature of the virtual world has advantages. For example: a) invisibility, interactivity, and multimodality for virtual things can be altered in real-time, b) context-aware things change their shape and/or behavior depending on user location and activity, and c) embedded computing for work or play be used in simulated contexts not suitable in the real world [118]. Many technical directions need exploration, such as the tradeoffs between embedded devices versus interaction devices, and between implicit versus explicit interaction [94]. 


\subsection{Semantic Web Drives Standards for Smarter/Faster e-Commerce}

Today, the top four technical directions for the Semantic Web are: 1) semantic-driven computation for identifying all solution possibilities and the best one, 2) automatic service composition via an orchestration model, 3) ontology-driven profiling using correct semantics for better access to solutions, and 4) semantic-driven decomposability to detect matching patterns in needs and solutions [183]. Here is a summary:

Semantic-Driven Computation. e-Commerce based on Web services allows any entity to trade with any other entity. Two frameworks are needed: a Web Services Modeling Framework (WSMF) [83] and Semantic Web Enabled Web Services (SWWS) [24]. WSMF is described below. The SWWS comprises five standards: coordination, semantics, discovery, trading, and negotiation. Future directions include: a) architecture for coordinated trading, b) semantics to mine social networks for commerce potential, c) product catalogues that suggest personalization possibilities, and d) intelligent agents for purchase negotiations [111].

Automatic Service Composition. Currently, the static Web has three key technologies: HTML, HTTP and URI for documents, and the dynamic Web three key technologies: WSDL, UDDI, and SOAP for services [83]. Today's Web Services Modeling Framework (WSMF) has four key technologies: a) ontologies, b) goal repositories, c) service descriptions, and d) mediators [83]. Future directions include: a) ontologies to define social network dynamics, b) repositories of prior successful commerce, c) an open orchestration model comprising product catalogs for personalization, and d) architecture for supporting purchases via intelligent agents [111].

Ontology-Driven Profiling. One possible future is to use "buying intention" as a new HTML anchor for tagging products to social network conversations. This tagging provides disambiguation semantics that enables more relevant ads, and simpler product discovery [125]. In this way, the strict publish-and-subscribe model of the semantic Web is augmented with buying intent history, and thus operates more along the lines of a query-for-content model [179]. Therefore, as soon as a prior buying intent is recognized, then previously used online ads can be invoked [111].

Semantic-Driven Composability. Composing Web services is a complex endeavor, and requires syntactic and semantic rules for success. Semantic composability rules include a) message, b) operation, c) qualities, and d) composition [113]. e-Business marketing exploits these rules to improve online ads: a) message = intent, b) operation = intent to buy, c) qualities = product personalization needs, and d) composition = intent plus needs matched to an offering. Such composability provides strong disambiguation semantics, and enables faster recognition of consumer buying intent [111]. 


\section{Technology Platform Directions}

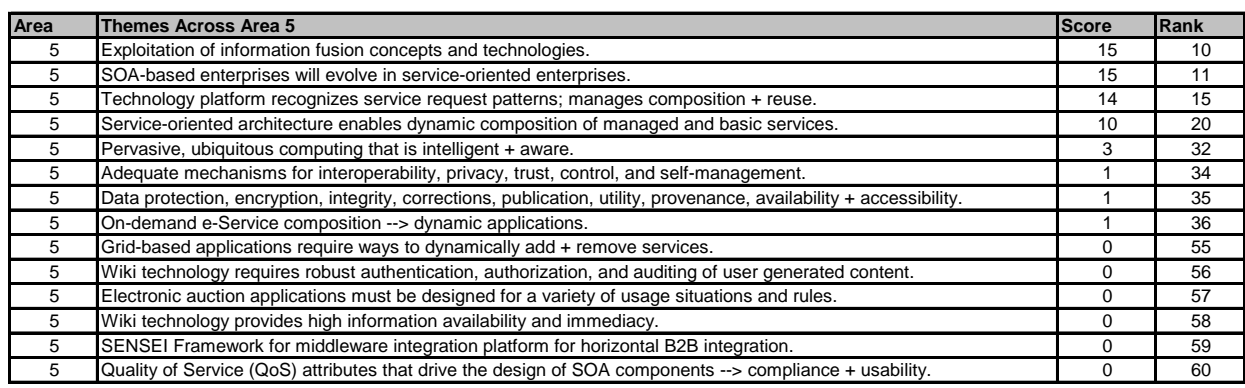

Table 5.Conference Themes and Importance for Technology Platforms (Scores are relative importance ratings. The ranking was done across all subject areas.)

A technology platform (TP) ensures optimum performance, availability, reliability, security, and intuitive data access across heterogeneous environments [20]. As such, a TP needs to adequately address the essential, desired features of current IT facilities: service orientation, support of autonomic behavior of entities, and context sensitivity [152]. We argue moreover that the actual "Cloud" direction [32] needs to be reflected as well in the current technology platform features. In the remaining of the section, we briefly outline and discuss each of these technology platform-related directions.

\subsection{Service-Oriented Computing}

Accommodating service orientation would require being consistent with the principles of the Service-Oriented Computing (SOC) Paradigm [146], considering the notion of "service" as a fundamental concept being nevertheless differently interpreted depending on the perspective; there are two main perspectives in this regard, namely the business perspective and the IT perspective. In a business context, a service involves the exchange of some action, performance or promise for value between a client and the provider [157]. In an IT context, a service refers to the external behavior of an IT system which behavior can be observed and experienced by the user of that system [155]. It is argued hence that considering these perspectives in combination allows SOC to bring together business and IT, by repeated aggregation of IT services into composite applications supporting business services that in turn are aggregated into business processes [168]. Thus, a SOC-inspired development of ICT applications would mean the ability to create new applications from existing services, independently of who provides these services, where they are provided, and how they are implemented [153]. Using the aforementioned, we derive the following requirements:

- Allow users to "play" with services at a high level;

- Maintain a sound link with the underlying technology;

- $\quad$ Reliably and flexibly establish and close connections, as needed;

- Support interoperability of full value;

- $\quad$ Properly handle all semantics;

- $\quad$ Align with advanced search facilities to enable service discovery. 


\subsection{Autonomic Computing}

In contrast to visions for human-centered information systems [33], sometimes there are many contexts where information systems can take autonomous action [19]. Technology platforms thus need to facilitate such "autonomic" behavior, which in turn requires the need for consistency within the principles of the Autonomic Computing Paradigm [151]. From this perspective, systems should be capable of adapting to dynamic, open environments on their own, with little or no human intervention.

The Autonomic Computing Paradigm [88] has been proposed as a way to reduce the cost of maintaining complex systems, and to increase the human ability to manage these systems properly. Autonomic Computing introduces a number of autonomic properties, such as self-configuring, self-healing, self-optimizing and self-protecting. Extending and enhancing a system with these properties is an important step towards a self-management system.

At least some fundamental concepts and architectural building blocks need to be considered for constructing self-managed systems with autonomic properties. The two main building blocks of an automatic computing architecture are autonomic managers and managed resources [77]. Managed resources are hardware or software components, for example a business application, a router or a database. A managed resource is managed by an autonomic manager. This autonomic manager forms the central part of the autonomic architecture. It collects data from managed resources, which is used for diagnosing failures and other unwanted behavior. The autonomic manager formalizes and executes remedy plans for the managed resource which are intended to correct the unwanted behavior. These arguments suggest requirements:

- $\quad$ Properly support technical IT systems acting on their own;

- Consider autonomous action (i.e. without triggers from “outside”);

- Act autonomously if the user interests would require such action;

- Yet protect users from inadequate or improper autonomic actions.

\subsection{Context-Aware Computing}

A key feature concerning any technology in service to human needs is its ability to adapt its behavior based on the user situation [178]. Technology platforms thus need to facilitate context-awareness, and do so consistent with the principles of the ContextAware Computing Paradigm [152]. Their underlying logic must acknowledge that end-user needs are not static, and are partially dependent on the particular context in which the end-user is situated. Context-aware systems are thus primarily motivated by their potential to increase user-perceived effectiveness (i.e. to provide services that better suit the needs of the end-user) by taking account changing conditions. We refer to the collection of conditions which characterize an end-user's immediate surroundings, which are relevant for the system in pursuit of user-perceived effectiveness, to be "end-user context," or "context" for short, in accordance to definitions found in today’s literature [40].

Context-aware systems can be somewhat effective if the end-user is mobile and uses a personal handheld device for the delivery of services. Mobility implies dynamic context, including most notably changing location. Regarding locations, different ones 
may have different social environments and different network access options, which offer opportunities for the provision of adaptive or value-added services based on these contexts. Especially in the mobile case, context changes are continuous, and a context-aware system may exploit this by providing near real-time adaptation during a service delivery session with its end-user. Taking the aforementioned into account, we derive the following requirements:

- Applications should be sensitive to user's entire situation;

- Applications must adapt their behavior when the situation changes;

- $\quad$ Platforms must guarantee adequate Quality-of-Context levels;

- $\quad$ Platforms support security for the end user;

- Platforms must enforce privacy of context information.

\subsection{Cloud Computing}

Emerging Enterprise Technologies are profoundly changing the way we think of IT. From economics and efficiency, to process and usage models, all these dimensions comprise the Cloud Computing Paradigm. Many organizations look to "externalize" IT systems and services as a potential cost-savings advantage, primarily by moving internally hosted IT services to external providers. Other organizations view "external” IT as potential disaster recovery systems, or as on-demand capacity to boost business continuity and customer service levels [80].

With regard to these issues, and considering the e-Business technology platforms directions, we need to take a closer look Cloud Computing. Most notably, we need to identify current emerging enterprise technologies, and how they might facilitate eBusiness and might produce a competitive advantage. There is hence a new wave of interest in the "Externalization of IT;" for example, anything-as-a-service (e.g. Software as a Service, Infrastructure as a Service, Platform as a Service, On Demand delivery, outsourcing, and so on). Taking the above background information into account, we derive the following requirements:

- $\quad$ Properly mediate between Cloud services and externalized services;

- $\quad$ Support the utilization of externalized services;

- $\quad$ Enforce Quality-of-Service standards with regard to externalized services.

\section{Summary and Conclusions}

e-Business Applications. Today's businesses are pressured by economic, technological, societal, and IT forces. In addition, Web 2.0 creates new strategic challenges never before considered by executives. Compounding these matters are the and digital native population who are demanding highly agile e-Business and personalized products. In response to these challenges, e-Business application development methods have appeared to better elicit context-based usage and operational requirements. There have also been many improvements in the System Development Life Cycle to ensure context-awareness is properly implemented. In addition, business sees that widening the scope of e-Business applications to every corner of the Internet can prove profita- 
ble. The big direction yet to be considered is giving the user real-time decisionmaking on adapting e-Business application to suit his or her current context.

Enterprise Engineering. In the area of enterprise engineering, two major challenges were identified. One challenge relates to understanding and managing the enterprise, and requires further work on Enterprise Architecture and enterprise ontologies. The other challenge follows from the necessity to connect applications and the trend to collaborate in business networks and form extended enterprises. Several issues exist here, at technical, semantic and organizational level, in order to achieve seamless integration and open interoperability. We also discussed three interesting enterprise engineering directions: cope with change, address value aspects, and move to virtual. Cope with change is concerned with developments that can help to address the problem of continuous change in business environments. Addressing value aspects relates to advances in business modeling that can capture economic value exchanges between participants in a business network. Finally, move to virtual is an evolutionary development of e-commerce towards the availability of more advanced business services for virtual market places, enabled by the Future Internet and associated technologies.

Mobility. m-Services and social networks offer new possibilities in many ways. For users, they can offer more flexibility and independence in planning activities, in shopping, in communication and getting entertainment. For companies, they will need to adapt business models, advertisements, product placements, communication channels, customer relationships and business processes to address new consumer behaviors. They will need to pay special attention to, and focus on, digital natives because this population is using mobile technology in new ways. Along with the many positive effects of new mobility come the concerns of privacy. An adequate reliable protection of information is therefore necessary to ensure user privacy and data integrity.

Collaboration \& e-Services. e-Business needs to recognize the groundswell of people now joining the digital native population. Part of that recognition means to reengineer the business to provide a fully customized product to each customer. In parallel, e-Business needs to be concerned with its electronic products, services and operations to ensure they all interoperate with other products, services and companies. Directionally, e-Business appears to be on a path to better understand and utilize multimedia social networks - a haven for digital natives. Thus, e-Businesses should start to see the value of virtual worlds, not only for the connection to digital natives, but also for the opportunity to offer product trials (i.e. via try before you buy demos) and advice (i.e. via product maven avatars). For products, there is growing recognition for intelligent user interfaces offering products that are highly attuned to the user's everchanging context. Operationally, the Semantic Web is becoming more commonplace in e-Business strategies, and R\&D is attempting to solve its issues and provide standards to commercial firms to enable better simplicity, reliability and speed.

Technology Platforms. In the area of technology platforms, two major challenges were rated as most important. One challenge relates to the necessity for delivering services through technology platforms in a way that hides the underlying technical 
complexity from the user, while at the same time keeping the vital link to the underlying technology. The second challenge relates to the need for most technology platforms to scale up when faced with the dynamic requirement of supporting a multitude of concurrent users, allowing all of them to adequately profile their requests as well as to establish and maintain dynamic collaborations. To meet these challenges, it is of essential importance to consider four relevant computing paradigms that complement each other: a) Service-Oriented Computing, b) Autonomic Computing, c) ContextAware Computing and d) Cloud Computing. Service-Oriented Computing concerns itself with service delivery, regardless of who is providing the service. Autonomic Computing focuses on the operation of the technical system itself, which must constantly consider is autonomous action is desired, required and/or appropriate. ContextAware Computing is simultaneously monitoring the user's ongoing changing situations, and subsequently altering the behavior of IT systems to match each situation. Cloud Computing concerns itself with the externalization of services and/or facilities through "The Cloud." To meet the aforementioned challenges, incorporating features related to each of these paradigms, in combination, is required.

\section{Acknowledgements}

The authors thank Dr. Maro Vlachopoulou from the University of Macedonia for her valuable insights on organizing workshop subject areas and their scope of concern. Thanks go to the ICETE organizing committee as well as its production team in the logistical design and delivery of the interactive workshop, which required a high amount of visual bandwidth and persistence over the three-day ICETE conference. In closing, the Conference Chairs, Dr. Joaquim Filipe and Dr. Mohammad Obaidat are to be acknowledged and thanked for their encouragement of holding this workshop at ICETE. The authors appreciate the opportunity to work with the entire conference to capture the common themes that occurred during conference dialogs, and their relative importance, for the current state of e-Business and for its possible future directions.

\section{References}

1. Abraham, P., Sikka, V., Simpson, G. (2010). Share Vs. Own: Software Reuse using Product Platforms. Proc. Intl. Conf. on e-Business (ICE-B’10), July.

2. Abrantes, S., Gouveia, L. (2010). A Study on the Usage of Mobile Devices in Collaborative Environments: An Approach based on Flow Experience. Proc. Intl.

Conf. on e-Business (ICE-B'10), July.

3. ACT4SOC, Inc. (2011). www.icsoft.org/workshops.asp.

4. Akyildiz, I. (2010). Nanonetworks: A New Frontier in Communications. Proc. Intl. Conf. on e-Business (ICE-B’10), July.

5. Allen, S., Tanev, S. \& Bailetti, T. (2009), "Components of Co-creation, Special Issue on Value Co-creation,” Open Source Business Review Online Journal, Nov. 
6. Allen, S., Tanev, S., Bailetti, T. (2009), Towards the Development of Research Methodology for Studying the Nature of Value Co-creation in Internet-Driven Businesses. Proc. 5th Intl. Conf. Software, Services \& Semantic Technologies, Oct.

7. Anderson, C., Wolff, M. (2010): Wired Magazine: The Web is dead. Long live the Internet. Wired September 2010. http://www.wired.com/magazine/ /2010/08/ff_webrip/2/ (2010-08-18).

8. Aris M. Ouksel, A., Sheth, A. (1999). Semantic Interoperability in Global Information Systems. ACM SIGMOD, 28(1).

9. Armbrust, M., Fox, A., Griffith, R., Joseph, A., Katz, R., Konwinski, A., Lee, G., Patterson, D., Rabkin, A., Stoica, I., Zaharia, M. (2009). Above the Clouds: A Berkeley View of Cloud Computing. UC Berkeley Reliable Adaptive Distributed Systems Laboratory, http://radlab.cs.berkeley.edu/.

10. Attkinson, B., Brady, S., Gilbert, D. Levine, D., O”Connor, P., Osisek, D., Spagna S., Wilson. (1995). IBM Intelligent Agents. In UNICOM Seminar Proceedings.

11. Badidi, E., Esmahi, L. (2010). A Quality of Context Driven Approach for the Selection of Context Services. Proc. Intl. Conf. on e-Business (ICE-B'10), July.

12. Balasubramanian, S., Mahajan, V. (2001). The Economic Leverage of the Virtual Community. Intl. Journal of Electronic Commerce, 5(3).

13. Berends, W., Folmer, E. (2010). Assessing Business Transaction Standards and Their Adoption: A Cross Case Analysis Between the SETU and Vektis Standards. Proc. Intl. Conf. on e-Business (ICE-B'10), July.

14. Berger, R. (2001). Automotive System Integrators. University of Michigan Transportation Research Institute.

15. Bernstein, M., Tan, F., Smith, G., Czerwinski, M., Horvitz, E. (2010). Personalization via Friendsourcing. ACM Trans. Computer-Human Interaction, 17(2).

16. Blumendorf, M., Lehmann, G., Albayrak, S. (2010). Bridging Models and Systems at Runtime to Build Adaptive User Interfaces. EICS'10: Proc. 2nd ACM Symposium on Engineering Interactive Computing Systems.

17. Boellstorf, T. (2008). Coming of Age in Second Life: An Anthropologist Explores the Virtually Human. United Kingdom: Princeton University Press.

18. Bourbakis, N. (2010). Information Security: The SCAN - Secure Processor with CryptoBiometrics Capabilities. Proc. Intl. Conf. on e-Business (ICE-B'10), July.

19. Brazier, F. (2010). Self-regulation for Transformation. Proc. Intl. Conf. Innovative Developments in ICT.

20. Brocade, Inc. (2010). www.brocade.com.

21. Brooks, F. (1987). "No Silver Bullet: Essence and Accidents of Software Engineering," IEEE Computer, 20(4).

22. Bulander, R., Decker, M., Kölmel, B., Schiefer, G. (2005): Advertising via Mobile Terminals, In: Filipe, J.; Greene, T. (Ed.): Proc. Intl. Conference on E-Business and Telecommunication Networks (ICE-B 2005), Reading, UK, October.

23. Bulander, R. (2010). A Conceptual Framework of Serious Games for Higher Education: A Conceptual Framework of the Game INNOV8 to Train Students in Business Process Modelling. Proc. Intl. Conf. on e-Business (ICE-B'10), July.

24. Bussler, C., Fensel, D., Maedche, A. (2002). Conceptual Architecture for Semantic Web Enabled Web Services. SIGMOD Record, 31(4).

25. Cassara, P., Melodia, T. (2010). Optimal Overlay Construction for Wireless Multimedia Social Networks. Associazione Gruppo Telecomunicazioni e Tecnologie dell”Informazione

26. Cereci, I., Kiliç, H. (2010). CAWP - A Combinatorial Auction Web Platform. Proc. Intl. Conf. on e-Business (ICE-B'10), July. 
27. Chan, K. (2006). A Fault Taxonomy for Web Service Composition. Xian Jiaotong University Journal, 40(8).

28. Chau, S., Turner, P. (2001). A Four Phase Model of e-Business Transformation amongst Small to Medium Sized Enterprises. ACIS 2001 Proceedings.

29. Chen, L. (2010). Intelligent Mobile Safety System to Educational Organization. Proc. Intl. Conf. on e-Business (ICE-B'10), July.

30. Chen, L., Pu, P. (2010). Experiments on the Preference-based Organization Interface in Recommender Systems. ACM Trans. Computer-Human Interaction, 17(1).

31. Cho, S., Lee, S., Moon, K. (2010). Fuzzy Decision Making of IT Governance. Proc. Intl. Conf. on e-Business (ICE-B'10), July.

32. Cloud, About the. (2010). www.aboutthecloud.nl.

33. Cordeiro, J., Filipe, J., Liu, K. (2009). Towards a Human-Oriented Approach to Information Systems Development. Proc. 3rd Intl. Workshop on Enterprise Sys. and Tech.

34. Cortimiglia, M. (2009). A Taxonomy Schema for Web 2.0 and Mobile 2.0 Applications. Proceedings of ICE-B 2009.

35. Debaty, P., Caswell, D. (2001). Uniform Web Presence Architecture for People, Places, and Things. IEEE Personal Communications, 8(4).

36. Decker, M. (2009): Prevention of Location-Spoofing - A Survey on Different Methods to Prevent the Manipulation of Locating-Technologies. Intl. Conf. e-Business (ICE-B”09).

37. Decker, M. (2008): Location Privacy - An Overview. In: m-business 2008: Proc. $7^{\text {th }}$ Intl. Conf. on Mobile Business (ICMB 08), July.

38. Decker, M., Bulander, R., Schiefer, G. (2006): A SME-friendly framework for the provision of mobile services. In: m-Business Revisited - From Speculation to Reality. $5^{\text {th }}$ Intl. Conf. on Mobile Business (ICMB 2006).

39. Decker, M., Schiefer, G. (2010): The SumoDacs-Project: Secure Mobile Data Access with a Tamperproof Hardware Token. Proc. of e-Challenges e-2010 Conference, IIMC, International Information Management Corporation, Warsaw, Poland, 2010

40. Dey, A., Abowd, G.D., Salber, D. (2001). A Conceptual Framework and Toolkit for Supporting Rapid Prototyping of Context-Aware Applications. Human Comp. Int., 16(2).

41. Diplaris, S., Kompatsiaris, I., Flores, A., Escriche, M, Sigurbjornsson, B., Garcia, L. (2010): Proc. Intl. Conf. on e-Business (ICE-B'10), July.

42. Djuric, P. (2010). From Nature to Methods and Back to Nature. Proc. Intl. Conf. on eBusiness (ICE-B'10), July.

43. Doerr, M (2003). The CIDOC Conceptual Reference Model: An Ontological Approach to Semantic Interoperability of Metadata. AI Magazine, 24(3).

44. Dietz, J.L.G. (2006). Enterprise Ontology - Theory and Methodology. Springer-Verlag.

45. Drossos, D.A., Fouskas, K. (2010). Mobile Advertising: Product Involvement and its Effect on Intention to Purchase. Intl. Conf. on Mobile Business (ICMB’10).

46. Dryer, C. (1997). Wizards, Guides, and Beyond: Rational and Empirical Methods for Selecting Optimal Intelligent User Interface Agents. 2nd Intl. Conf. Intel. User Interfaces.

47. Dyché, J. (2002): The CRM-Handbook. Boston: Addison-Wesley.

48. Ehn, P. (1990). Work-Oriented Design of Computer Artifacts. L. Erlbaum Associates Inc.

49. Eliassi-Rad, T., Shavlik, J. (2002). A System for Building Intelligent Agents that Learn to Retrieve and Extract Information. Journal of User Modeling and User-Adapted Interaction, 13(1-2).

50. Ervasti, M. (2008). Adoption of Mobile Services in Finland. Proc. of ICE-B 2008.

51. Estrin, D. (2010). Participatory Sensing: Application and Architecture. IEEE Internet Computing, 14(1). 
52. Eurich, M., Boutellier, R. (2010). Middleware Integration Platforms: A New Challenge to Business Models of ICT Companies. Unleashing the Business Potential of Horizontalization. Proc. Intl. Conf. on e-Business (ICE-B'10), July.

53. Fang, Z. (2002). E-Government in Digital Era: Concept, Practice, and Development. Intl. Journal of The Computer, The Internet and Management, 10(2).

54. Forbes Blog. (2010). Milo and Kate Live Demo. http://blogs.forbes.com/velocity/2010/07/13/milo-and-kate-live-demo-cool-creepy/. Jul. 132010.

55. Frank, A. (2010). Dependable Distributed Testing: Can the Online Proctor be Reliably Computerized? Proc. Intl. Conf. on e-Business (ICE-B’10), July.

56. Fu, W., Kannampallil, T., Kang, T., He, J. (2010). Semantic Imitation in Social Tagging. ACM Trans. Computer-Human Interaction 17(3).

57. Gartner Research (2008): Press Release: Gartner Identifies Top Ten Disruptive Technologies for 2008 to 2012. (http://www.gartner.com/it/page.jsp?id=681107) (2010-08-18).

58. Geyer-Schulz, A., Ovelgöenne, M., Sonnenbichler, A. (2010). Getting Help in a Crowd: A Social Emergency Alert Service. Proc. Intl. Conf. on e-Business (ICE-B'10), July.

59. Gordijn, J. (2005). Comparing Two Business Model Ontologies for Designing e-Business. Proceedings of the 8th BLED Conference.

60. Gordijn, J., Wieringa, R. (2010). A Value-Oriented Approach to e-Business Process Design. in Advanced Information Systems Engineering, LNCS, Vol. 2681.

61. Gottschalk, K. (2002). Introduction to Web Services Architecture. IBM Sys. J., 41(2).

62. Gruber, T.R. (1995). Towards principles for the design of ontologies used for knowledge sharing. International Journal of Human-Computer Studies, 43(5-6).

63. Gustas, A. and Gustiené, P. (2003). Towards the Enterprise Engineering Approach for Information System Modeling Across Organizational and Technical Boundaries. Proc. 5th Intl. Conf. on Enterprise Info. Sys., Vol. 3.

64. Hamill, L., Nigel Gilbert, N. (2009, February). Social Circles: A Simple Structure for Agent-Based Social Network Models. Journal of Artificial Societies and Social Simulation. 12(2).

65. Heflin, J., Hendler, J. (2000). Semantic Interoperability on the Web. Conf. on Extreme Markup Languages 2000.

66. Heller, M., Allgaier, M. (2010). Model-Based Service Integration for Extensible Enterprise Systems with Adaptation Patterns. Proc. Intl. Conf. on e-Business (ICE-B’10), July.

67. Heravi, B., Bell, D., Lycett, M., Green, S., Snelling, D. (2010). Towards Ontology Based e-Business Standards. Proc. Intl. Conf. on e-Business (ICE-B'10), July.

68. Hippner, H. (2004): CRM - Grundlagen, Ziele und Konzepte. In: Hippner, H, Wilde, K. D.: Grundlagen des CRM. Gabler, Wiesbaden, pp. 13-42.

69. Hof, R. (2006). Web 2.0 Has Corporate America Spinning. Bloomberg Business Week Online, June 5.

70. Holzinger, A., Mayr, S., Slany. W., Debevc, M. (2010). The Influence of AJAX on Web Usability. Proc. Intl. Conf. on e-Business (ICE-B'10), July.

71. Holzinger, A., Schlögl, M., Peischl, B., Debevc, M. (2010). Preferences of Handwriting Recognition on Mobile Information Systems in Medicine: Improving Handwriting Algorithm on the Basis of Real-life Usability Research. Intl. Conf. on e-Business (ICE-B'10).

72. Holzinger, A., Struggl, K., Debevc, M. (2010). Applying Model-View-Controller (MVC) in design and Development of Information Systems: An Example of Smart Assistive Script Breakdown in an e-Business Application. Proc. Intl. Conf. on e-Business (ICE-B’10), July.

(C)Authors. (2011). in e-Business and Telecommunications, (ed.) Filipe, J., Obaidat, M. 
73. Holzinger, K., Holzinger, A., Safran, C., Koiner-Erath, G., Weippl, E. (2010). Use of Wiki Systems in Archaeology: Privacy, Security and Data Protection as Key Problems. Proc. Intl. Conf. on e-Business (ICE-B'10), July.

74. Hu, S., Chen, B. (2010). Peer-to-Peer 3D Streaming. IEEE Internet Computing, 14(2).

75. Huhns, M. (2010). Software Agents: The Future of Web Services. in Agent Technologies, Infrastructures, Tools, Applications for E-Services LNCS Vol. 2592.

76. Huysmans, P., Bellens, D., Nuffel, D., Ven, K. (2010). Designing Enterprise Architectures Based on Systems Theoretic Stability. Proc. Intl. Conf. on e-Business (ICE-B'10), July.

77. IBM, Inc. (2010). www.ibm.com.

78. Interone. (2010). Interone GmbH Study: The-Age-Of-On (http://www.interone.de/iphonestudie/), Aug. 18.

79. Irmak, U., Kraft, R. (2010). A Scalable Machine-Learning Approach for Semi-Structured Named Entity Recognition. Proc. 19th Intl. Conf. on the World Wide Web.

80. Ivanov, I. (2009). Emerging Utility and Cloud computing Models. Proc. 3rd Intl. Workshop on Enterprise Systems and Technology.

81. Jensen, C., Lonsdale, H., Wynn, E., Cao, J., Slater, M., Dietterich, T. (2010). The Life and Times of Files and Information: A Study of Desktop Provenance. Proc. 28th Intl. Conf. Human Factors in Comp. Sys.

82. Jin, J., Maheswaran, R., Sanchez, R., Szekely, P. (2007). VizScript: Visualizing Complex Interactions in Multi-Agent Systems. Proc. 12th Intl. Conf. Intelligent User Interfaces, Jan.

83. Kajan, E. (2004). The Maturity of Open Systems for B2B. ACM SIGEcom Exchanges, 5(2), Nov.

84. Kapurubandara, M., Hol, A., Ginige, A. (2010). SMES in developed and Developing Countries treading Simial Paths Towards e-Transformation. Proc. Intl. Conf. on eBusiness (ICE-B'10), July.

85. Karp, S. (2006). What If Media 2.0 Is Less Profitable Than Media 1.0? Publishing 2.0. http://publishing2.com/2006/04/23/what-if-media-20-is-less-profitable-than-media-10/

86. Kartalopoulos, S. (2010). Chaotic Quantum Cryptography: The Ultimate for Network Security. Proc. Intl. Conf. on e-Business (ICE-B'10), July.

87. Kauffman, R., Walden, E. (2001). Economics and Electronic Commerce: Survey and Directions for Research. Intl. Journal of Electronic Commerce, 5(4).

88. Kephart, J., Chess, D. (2003). The vision of Autonomic Computing. IEEE Computer Society Press.

89. Khaddage, F., Lanham, E., Zhou, W. (2009): A Mobile Learning Model for Universities. Intl. Journal of Interactive Mobile Tech. (iJIM), Vol. 3 (2009).

90. Kim, D., Shipman, F. (2010). Interpretation and Visualization of User History in a Spatial Hypertext System. Proc. 21st ACM Conf. on Hypertext and Hypermedia.

91. Ko, M., Cheek, G., Shehab, M. (2010). Social-Networks Connect Services. IEEE Computer, 43(8).

92. Kortuem, G., Kawsar, F., Fitton, D., Sundramoorthy, V. (2010). Smart Object Building Blocks on The Internet of Things. IEEE Internet Computing, 14(1).

93. Kosonen, M. (2008). Knowledge Sharing in Virtual Communities. Doctoral Thesis. Lappeenranta University.

94. Kranz, M., Holleis, P., Schmidt, A. (2010). Embedded Interaction: Interacting with the Internet of Things. IEEE Internet Computing, 14(2).

95. Krasonikolakis, I., Vrechopoulos, A., Pouloudi, A. (2010). User's Personality Traits in the Context of Virtual Reality. Proc. Intl. Conf. on e-Business (ICE-B'10), July.

96. Lakshmanan, G., Oberhofer, M. (2010). Knowledge Discovery in the Blogsphere. IEEE Internet Computing, 14(2). 
97. Lankhorst, M. et al. (2005). Enterprise Architecture at Work: Modeling, Communication and Analysis. Springer-Verlag.

98. Laugesen, J, Yuan, Y. (2010): What factors contributed to the success of Apple's iPhone? In: 9th Intl. Conf. on Mobile Business (ICMB 2010), June.

99. Lauw, H., Shafer, J., Agrawal, R., Ntoulas, A. (2010). Homophily in the Digial World. IEEE Internet Computing, 14(2).

100. Law, M.; Lau, T., Wong, Y.H. (2003): From customer Relationship Management to Customer-Managed-Relationship: Unraveling the Paradox with a Co-creative Perspective. In: Marketing Intelligence \& Planning. 21/1 (2003), pp. 51-60.

101. Li, C., Bernoff, J. (2008): Groundswell: Winning in a World Transformed. Massachusetts: Social Technologies, Inc.

102. Li, T., Hsu, S. (2004). An Intelligent 3D User Interface Adapting to User Control Behaviors. IUI”04: Proc. 9th Intl. Conf. Intelligent User Interfaces, Jan.

103. Liestol, G. (2009): Situated Simulations: A Prototyped Augmented Reality Genre for Learning on the iPhone. Intl. Journal of Interactive Mobile Tech. (iJIM), Vol. 3 (2009).

104. Lin, J., Li, X., Li, L. (2010). Integrating Mobile Agent and Context-Aware Workflow Analysis for m-Commerce Applications. Proc. Intl. Conf. on e-Business (ICE-B'10), July.

105. Lin, R., Lin, C. (2010). From Digital Archives to e-Business: A Case Study on Turning "Art” into "Business." Proc. Intl. Conf. on e-Business (ICE-B'10), July.

106. Lin, W., Zhao, V., Liu, K. (2009). Incentive Cooperation Strategies for Peer-to-Peer Live Multimedia Streaming Social Networks. IEEE Trans. on Multimedia, 11(3), April.

107. Luftman, J. (2004). Assessing Business-IT Alignment Maturity. In van Grimbergen (Ed.), Strategies for Information Technology Governance. Idea Group Inc.

108. Lugrin, J., Cavazza, M. (2007). Making Sense of Virtual Environments: Action Representation, Grounding and Common Sense. Proc. Intl. Conf. on Intel. User Interfaces, Jan.

109. Maes, P., Mistry, P. (2009). SixthSense Demonstration. http://www.ted.com/talks/pattie_maes_demos_the_sixth_sense.html, Feb.

110. Manno, M., Primo, P., Passaro, G., Leggio, E., Barbera, R., Giuseppe Andronico, G., Bruno, R., Giorgio, E., Fargetta, M., Rocca, G., Monforte, S., Scardaci, D., Scibilia, F. (2010). The COMETA e-Infrastructure: A Platform for Business Applications in Sicily. Proc. Intl. Conf. on e-Business (ICE-B’10), July.

111. Marca, D. (2010). e-Business \& Social Networks: Tapping Dynamic Niche Markets Using Language-Action \& Artificial Intelligence. in in e-Business and Telecommunications, (ed.) Filipe, J., Obaidat, M., Springer-Verlag.

112. McEnvoy, G. (2009). Using Clouds to Address Grid Limitations. Proc. of 6th Intl. Workshop on Middleware for Grid Computing.

113. Medjahed, B. (2003). Composing Web Services on the Semantic Web. VLDB J., Vol. 12.

114. Medjahed, B., Bouguettaya, A., Elmagarmid, A. (2003). ComposingWeb services on the Semantic Web. VLDB J., Vol. 12.

115. Mohomed, I. (2010). Enabling Mobile Application Mashups with Merlion. Proc. 11th Workshop on Mobile Comp. Sys. \& Apps.

116. Morimoto, S. (2010). A Case Study of the e-Money Application in Japanese Public Transportation. Proc. Intl. Conf. on e-Business (ICE-B'10), July.

117. Motta, E. (2006) Next Generation Semantic Web Applications. Lecture Notes in Computer Science, No. 4185, Springer-Verlag.

118. Mulligan, G. (2010). The Internet of Things: Here Now and Coming Soon. IEEE Internet Computing, 14(1).

119. Myers, B., Hudson, S., Pausch, R. (2000). Past, Present, and Future of User Interface Software Tools. ACM Trans. Computer-Human Interaction, 7(1). 
120. Norman, D., Draper, S. (1986). User Centered System Design; New Perspectives on Human-Computer Interaction. L. Erlbaum Associates Inc.

121. Palfrey, J., Gasser, U. (2008). Born Digital. Philadelphia: Basic Books.

122. Panetto, H. and Molina, A. (2008). Enterprise Integration and Interoperability in Manufacturing Systems: Trends and Issues. Computer in Industry, 59(7).

123. Papageorgiou, N., Verginadis, Y., Apostolou, D., Mentzas, G. (2010). Semantic Interoperability on e-Services in Collaborative Networked Organizations. Proc. Intl. Conf. on eBusiness (ICE-B'10), July.

124. Papazoglou, M. (2003). Service-Oriented Computing. CACM, 46(10).

125. Parkhomenko, O., Lee, Y., Park, E. (2003). Ontology-Driven Peer Profiling in Peer-toPeer Enabled Semantic Web. CIKM”03, Nov.

126. Parreiras, F. (2001). E-Business Challenges and Trends. Executive Report. Nucleo de Estulos em Tecnologies para Informaceo e Conhecimento.

127. Payne, A., Storbacka, K., Frow, P. (2008). Managing the Co-Creation of Value. Journal of the Academy of Marketing Sciences, 36(1).

128. Petroczi, A. (2007). Measuring tie-Strength in Virtual Networks. Connections. 27(2).

129. Plessis, C. (2010). Mobile Marketing Communications to the Youth: An Analysis of the MXit Platform. Proc. Intl. Conf. on e-Business (ICE-B’10), July.

130. Pokrae, S., Reichert, M., Steen, M., Wiering, R. (2005). Semantic and Pragmatic Interoperability: A Model for Understanding. http://www.ceur-ws.org/Vol-160/paper21.pdf .

131. Porter, M. (2001). Strategy and the Internet. Harvard Business Review, 79(3).

132. Postech, G., Pan, S. (2007). Building Ubiquitous and Robust Speech and Natural Language Interfaces. Proc. 12th Intl. Conf. Intelligent User Interfaces, Jan.

133. Prahalad, C., Krishnan, M. (2008). The New Age of Innovation. New York: McGraw Hill.

134. Prahalad, C., Ramaswamy, V. (2004). The Future of Competition: Co-Creating Unique Value with customers. Boston: Harvard Business School Press.

135. Radovilsky, Z. (2009). E-Commerce Management. www.universityreaders.com.

136. Rajkumar, B. (2009). Cloud Computing and Emerging IT Platforms. Future Generation Computer Systems. Elsevier Press, Inc.

137. Robertson, B. (2004). Enriching the Value Chain: Infrastructure Strategies. Intel Press.

138. Rogers, E. M., 1995: Diffusion of innovations, Free Press. New York, USA, 4th edition.

139. Royo, C., Rueda, J., Rugnon, O., Fuentes, B., Castro, A. (2010). Business Terms: Model for a Telecom Operator Business View of SLA. Intl. Conf. on e-Business (ICE-B'10).

140. Ruokolainen, T., Kutvonen, L. (2006). Interoperability in Service-Based Communities. BPM 2005 Workshops, LNCS Vol. 3812, Springer-Verlag.

141. Sadoun B., Saleh, B. (2010). A Geographic Information System (GIS) to Define Indicatiors for Development and Planning in Jordan. Proc. Intl. Conf. on e-Business (ICE-B’10).

142. Sawhney, M., Verona, G., Prandelli, E. (2005). Collaborating to Create: The Internet as a Platform for Customer Engagement in Product Innovation. J. of Inter. Marketing, 19(4).

143. Schauer, B., Zeiller, M., Riedl, D. (2010). Reviewing the e-Collaboration Marketplace: A Survey of Electronic Collaboration Systems. Proc. Intl. Conf. on e-Business (ICE-B’10).

144. Schilit, B. N., Adams, N. I. \& Want R., 1994: Context-Aware Computing Applications. In: Proceedings of the IEEE Workshop on Mobile Computing Systems and Applications.

145. Schneider, G. (2009). Electronic Commerce. Cengage Learning, Inc.

146. Sinderen, M. van (2009). From Service-Oriented Architecture to Service-Oriented Enterprise. Proc. 3rd Intl. Workshop on Enterprise Systems and Technology.

147. Sinderen, M. van (2008). Challenges and Solutions in Enterprise Computing. Enterprise Information Systems, 2(4).

CAuthors. (2011). in e-Business and Telecommunications, (ed.) Filipe, J., Obaidat, M. 
148. Shankar, A., Louis, S., Dascalu, S., Hayes, L., Houmanfar, R. (2007). User-Context for Adaptive User Interfaces. Proc. 12th Intl. Conf. Intelligent User Interfaces, Jan.

149. Sharma, S. (2010). The New Way of Business. IEEE Internet Computing, 14(1).

150. Shevade, B., Sundaram, H., Xie, L. (2007). Modeling Personal and Social Network Context for Event Annotation in Images. Proc. 7th ACM/IEEE-CS Conf. on Digital Libraries.

151. Shishkov, B., Warnier, M., Van Sinderen, M. (2010). On the Application of Autonomic and Context Aware-Computing to support Home Energy Management. Proc. 10th Intl. Conf. on Enterprise Info. Sys.

152. Shishkov, B. (2010). Methodological Support for the Design of Enterprise Information Systems with SDBC, Towards Distributed, Service-Oriented, and Context-Aware Solutions. Proc. 3rd Intl. Workshop on Enterprise Sys. and Tech.

153. Shishkov. B., Van Sinderen, M., (2009). Service-Oriented Coordination Platform for Technology-Enhanced Learning. Proc. 3rd Intl. Workshop on Enterprise Sys. and Tech.

154. Shishkov, B., van Sinderen, M., Verbraeck, A. (2009). Towards Flexible Inter-enterprise Collaboration: A Supply Chain Perspective. Proc. 9th Intl. Conf. on Enterprise Info. Sys.

155. Shishkov, B., van Sinderen, M., Quartel, D. (2006). SOA-Driven Business-Software Alignment. IEEE Intl. Conf. on e-Business Engineering.

156. Shu, W. (2005). Web Engineering Principles and Techniques. London: Idea Group Inc.

157. Spohrer, J., Maglio, P.P., Bailey, J., Gruhl, D. (2007). Steps Toward a Science of Service Systems. IEEE Computer, 40(1).

158. Tan, B., Tang, N., Forrester, P. (2004). Application of QFD for e-Business Planning. Production Planning \& Control, 15(8).

159. Tanev, S., durchev, P., Milyakov, H., Ruskov, P., Allen, S., Bailetti, T. (2010). Value Cocreation in Open Source Firms and Beyond. Open Source Innovation Workshop, Strasbourg, France, Feb.

160. Tapscott, D. (2009). Grown Up Digital. New York: McGraw-Hill.

161. Tarasewich, P. (2002). Issues in Mobile e-Commerce. Communications of the Association for Information Systems. Vol. 8.

162. Tian, Y., Srivastava, J., Huang, T., Contractor, N. (2010). Social Media Computing. IEEE Computer, 43(8).

163. Toffler A. (1983): The Third Wave - The rise of the Prosumer. Goldmann Publishers.

164. Toffler, A. (1984). The Third Wave: A Classic Study of Tomorrow. Bantam Books.

165. Torrone, P. (2004). Kryptonite Evolution 2000 U- Lock hacked by a Bic pen. engadget blog post.

166. Tsagkani, C. (2010). Business Process Flexibility: Evaluation Criteria and Guidelines. Proc. Intl. Conf. on e-Business (ICE-B’10), July.

167. Ueki, Y. (2003). E-Business Innovation and Customs Renovation. Executive Report. Chile Division of International Trade.

168. Unger, T., Mietzner, R., Leymann, F. (2009). Customer-defined Service Level Agreements for Composite Applications. Enterprise Information Systems, 3(3).

169. Unhelkar, B. Ginige, A. (2010). A Framework to Derive Holistic Business Transformation Processes. Proc. Intl. Conf. on e-Business (ICE-B'10), July.

170. Vallecillo, A., Hernández, J., Troya, J. (1999). Object Interoperability. In Object-Oriented Technology. ECOOP”99 Workshop, LNCS Vol. 1743, Springer-Verlag.

171. Vernadat, F.B. (2010). Technical, Semantic and Organizational Issues of Enterprise Interoperability and Networking. Annual Reviews in Control, 34(1).

172. Vernadat, F.B. (1996). Enterprise Modeling and Integration: Principles and Applications. Chapman \& Hall.

173. Vlachopoulou, M. (2009). E-Business Trends Notes. University of Macedonia. 
174. Wang, F., Zeng, D., Hendler, J., Zhang, Q.,, Feng, Z., Gao, Y., Wang, H., Lai, G. (2010). A Study of the Human Flesh Search (HFS) Search Engine. IEEE Computer, 43(8).

175. Wen, Z., Zhou, M., Aggarwal, V. (2007). Context-Aware, Adaptive Information Retrieval for Investigative Tasks. Proc. 12th Intl. Conf. Intelligent User Interfaces, Jan.

176. Whinston, A. (1997). Economics of Electronic Commerce. Pearson Education, Inc.

177. Wikipedia, 2010. http://en.wikipedia.org/wiki/Platform_technology.

178. Wikipedia, 2010. http://en.wikipedia.org/wiki/Context_awareness.

179. Xiao, L, Wang, Y., Shen, D., Acero, A. (2010). Learning with Click Graph for Query Intent Classification. ACM Trans. for Info. Sys. 28(3).

180. Yang, H., Lay, Y., Tsao, W., Lay, J. (2010). The Impact of the Internet on Social Anxiety and Learning Adaptability for Young Adult Internet Users. Proc. Intl. Conf. on e-Business (ICE-B'10), July.

181. Yardi, S., Poole, E. (2009). Patterns of Personalization in an Online Tech Support Board. Proc. 4th Intl. Conf. on Communities and Technologies.

182. Yoon, C., Lee, K. (2010). A Measurement Instrument for Individual Information Competency in an Enterprise Information Enviornment. Intl. Conf. on e-Business (ICE-B'10).

183. Yu, Q., Liu, X., Bouguettaya, A., Medjahed, B. (2008). Deploying and managing Web services. The VLDB Journal, Vol. 17.

183. Zachman, J. (1987). A Framework for Information Systems Architecture. IBM Systems Journal, 26(3).

184. Zašcerinska, J., Ahrens, A. (2010). e-Business Applications in Engineering Education. Proc. Intl. Conf. on e-Business (ICE-B’10), July.

185. Zeiris, E., Ziema, M. (2010). SOA Based e-Business Systems Design. Proc. Intl. Conf. on e-Business (ICE-B'10), July.

186. Zhao, V., Liny, W., Liuy, K. (2009). Behavior Modeling and Forensics for Multimedia Social Networks: A Case Study in Multimedia Fingerprinting. IEEE Signal Processing Magazine, 26(1).

187. Zunjarwad, A., Sudaram, H., Xie, L. (2007). Contextual Wisdom: Social Relations and Correlations for Multimedia Event Annotation. Intl. Conf. on Multimedia, Sep.

188. Marques Pereira, C., Sousa, P. (2004). A Method to Define an Enterprise Architecture Using the Zachman Framework. Proc. of the 2004 ACM Symp. on Applied Computing.

189. Winter, R., Fischer, R. (2006). Essential Layers, Artifacts, and Dependencies of Enterprise Architecture. Proc. of the 10th IEEE Intl. EDOC Enterprise Computing Conf. Workshops.

190. Dai, Q. and Kauffman, R.J. (2002). Business Models for Internet-based B2B Electronic Markets. International Journal of Electronic Commerce, 6(4).

191. Barros, A.P., Dumas, M. (2006). The Rise of Web Service Ecosystems. IT Prof., 8 (5).

192. Buyya, R., Shin Yeo, C., Venugopal, S. (2008). Market-oriented Cloud Computing: Vision, Hype, and Reality for Delivering IT Services as Computing Utilities. Proc. of the 10th IEEE Intl. Conf. on High Performance Computing and Communication.

193. The Open Group (2006). The Open Group Architecture Framework - Part II (Architecture Development Method). Version 8.1.1, Document G063.

194. Frankel, D.S., et al. (2003). The Zachman Framework and the OMG's Model Driven Architecture. Business Process Trends, White Paper, http://www.bptrends.com/.

195. Favre, J.-M. (2004). CaCOphoNy: Metamodel-driven Software Architecture Reconstruction. In: Proc. 11th Working Conf. on Reverse Engineering.

196. Fui-Hoon Nah, F., Lee-Lau, J., Kuang, J. (2001). Critical Factors for Successful Implementation of Enterprise Systems. Business Process Management Journal, 7(3).

197. Pateli, A.G., Giaglis, G.M. (2003). A Framework for Understanding and Analysing eBusiness Models. Proc. 16th Bled eCommerce Conference. 
198. Mutschler, B., Bumiller, J., Reichert, M.U. (2006). Designing an Economic-driven Evaluation Framework for Process-oriented Software Technologies. Proc. 28th Intl. Conf. on Software Engineering (ICSE'06).

199. Wieringa, R.J., Gordijn, J. , Eck, P.A.T. van (2005b). Value-Based Business-IT Alignment in Networked Constellations of Enterprises. Proc. 1st Intl. Workshop on Requirements Engineering for Business Need and IT Alignment (REBNITA 2005).

200. Mantovaneli Pessoa, R., Sinderen, M. van, Quartel, D. (2009). Towards Requirements Elicitation in Service-oriented Business Networks Using Value and Goal Modelling. Proc. 4th Intl. Conf. on Software and Data Technologies (ICSOFT 2009).

201. Zlatev, Z.V., Wombacher, A. (2005). Consistency between e3-value Models and Activity Diagrams in a Multi-Perspective Development Method. Proc. Intl. Conf. on Cooperative Information Systems, LNCS 3760, Springer.

202. Fatemi, H., Sinderen, M. van, Wieringa, R. (2010). Value-Oriented Coordination Process Modeling. Proc. 8th Intl. Conf. on Business Process Management LNCS 6336, Springer.

203. Ilayperuma, T., Zdravkovic, J. (2010). Exploring Business Value Models from the Interorganizational Collaboration Perspective. Proc. 2010 ACM Symp. on Applied Computing.

204. Schuster, R., et al. (2010). From Economic Drivers to B2B Process Models: A Mapping from REA to UMM. Business Information Systems, LNBIP 47, Part 4, Springer-Verlag.

205. Johannesson, P., et al. (2009). Enterprise Modelling for Value Based Service Analysis. The Practice of Enterprise Modeling, LNBIP 15, Part 4, Springer.

206. Choi, S.-Y., Whinston, A., Stahl, D. (1997). Economics of Electronic Commerce. Macmillan Computer Publishing.

207. Friedman, D., Steed, A., Slater, M. (2007). Spatial Behaviour in Second Life. Intelligent Virtual agents, LNCS 4722, Springer-Verlag.

208. Gavras, A. et al. (2007). Future Internet Research and Experimentation: The FIRE Initiative. ACM SIGCOMMM Computer Communication Review, 37(3).

209. Welbourne, E. et al. (2009). Building the Internet of Things using RFID. IEEE Internet Computing, 13(3).

210. Crowley, J.L., Reignier, P., Coutaz, J. Context Aware Services. True Visions - The Emergence of Ambient Intelligence, Springer-Verlag.

211. Picinelli, G., Di Vitantonio, G., Mokrushin, L. (2001). Dynamic Service Aggregation in Electronic Marketplaces. Computer Networks, 37(2).

212. Kutvonen, L., Metso, J., Ruokolainen, T. (2005). Inter-Enterprise Collaboration Management in Dynamic Business Networks. Proc. On the Move to Meaningful Internet Systems 2005: COOPIS, DOA, and ODBASE, LNCS 3760, Springer-Verlag.

213. Sun, W. et al. (2008). Software as a Service: Configuration and Customization Perspectives. Proc. IEEE Congress on Services, Part II, IEEE Computer Society. 